\title{
Flipped classroom and ICTs as the tools to reach key competences
}

\author{
Sanchez Peñaranda , David; Naturil Alfonso , Carmen; Marco Jiménez, José \\ Salvador, Francisco, and Antón, Vicente \\ Animal Science Department, Universidad Politècnica de València, Spain.
}

\begin{abstract}
The contemporary society demands proffessionals with competences directly conected to information and communication technology (ICT). In fact, the ICTs have registered a relevant advance through last decades, making possible the implantation of new educational strategies like: the inverted or flipped model. Nevertheless, ICT have been used in a superficial manner at educational system, even at higher education system.

The aim of the present work will be the description of an innovative teaching programme which proposes the implantation of flipped classroom using ICTs to reach the key competences in two environments: students using English as foreign/second-language and students using Spanish as first language.

The key competences will be developed through 5 e-learning activities. The students, outside of the classroom, will perform the tasks using ICTs and afterwards delivering the competence evidence. Once in classroom, the students should make a presentation of their work and open discussion will be performed.

The teacher based on the indicators of achievement and competence evidence will be able to assess the grade of fulfillment of the key competence. Finally, the effectiveness of the teaching project will be evaluated making the comparison between the competence achievement before and after teaching programme implantation.
\end{abstract}

Keywords: flipped classroom, ICTs, key competences, 


\section{Introduction}

The contemporary society demands new competences to both teachers and students, and these competences are related to e-learning activities. High education is required to use information and communication technology (ICT), thus teachers should be prepared to stimulate students through integration of ICT (Røkenes \& Krumsvik, 2016). Nevertheless, the presence of digital tools and digital competence development in the university is limited. ICT tools have been used in a superficial manner, such as lesson planning, personal communication or word processing (Drent \& Meelissen, 2008), and digital competence is limited to basic skills including office tools and social media (Valtonen et al., 2013).

On the other hand, recently, a different model of teaching have been proposed: the inverted or flipped model. Flipped Classroom is known as is an instructional strategy that combines online digital media with traditional classroom methods, but reversing the traditional learning environment by delivering instructional content, often online, outside of the classroom. Therefore, using this methodology, the students are able to acquire the learning outcomes outside of the classroom, usually using ICTs (Khan, 2012). In fact, the huge advance of ITCs have allowed that flipped classroom methodology had become a reality. Thanks to ICTs is possible to create stimulating learning environments that allow students to solve realistic problems and develop higher-order cognitive skills (Lajoie \& Azevedo, 2000).

A relevant advantage of inverted classroom methodology is the fact that can be combined with ICTs to achieve the key competences. European Parliament and the Council, in December 2006, defines the recommendation on European Key Competences, in order to make teaching and learning more oriented towards competence development (Halász \& Michel, 2011). European recommendation did not make any reference to behaviour and to learning environments, but the need to think the learning outcomes in terms of competences, is not possible without modifying educational methodolies.

In conclusion, the flipped classroom is an innovative educational methodology, flexible enough to be combined with ICTs in order to make mores feisable the evaluation and so on the achievement of the key and transversal competences.

\section{Objectives}

The aim of the currentstudy is the description of an innovative teaching programme which proposes the implantation of flipped classroom using ICTs to reach the key competences in two environments: students included in Content and language integrated learning (CLIL) programmes (using English as foreign/second-language) and students included in groups using Spanish as first language. 


\section{Methodology}

\subsection{Context and Participants}

The innovative teaching project will be applied at Universitat Politècnica de València (UPV), particularly in the Degree in Biotechnology (http://www.upv.es/titulaciones/GB/index-en.html), which includes a new programme called: Grupos de Alto Rendimiento Académico: Grupos ARA (https://www.upv.es/contenidos/ARA/). This programme was designed by the local government (http://www.ceice.gva.es/web/universidad/grupos-de-alto-rendimiento; Generalitat Valenciana) to reinforce the potential of the outstanding students in order to help them to achieve the highest academic performance.

The teaching project will be applied in the annual subject: "Animal and Human Physiology". The subject is considered as a basic training course, being divided into two teaching groups: Standard group, using Spanish as working language and ARA group, using English as working-language. The English group, in order to ensure the achievement of the learning outcomes, the students must certify having a minimum of B2 English level, based on the Common European Framework.

The teaching activities will be carried out by 2 assistant professors, 1 lecturer and 1 professor. The programme has been designed to be applied in 5 lessons of 1 hour, corresponding to 5 seminars. The maximum number of students by seminar is 25 . Thus, the Spanish group ( $\sim 100$ students) will be divided in 4 sub-groups of $\sim 25$ students. Taking into account that the ARA group is limited to 25 students, only one seminar group will be stablished.

\subsection{Key and Transversal Competences}

The subject has been designed to achieve a set of key competeces:

- Ability to search and use information

- Competence for continuous learning

- Ability to solve complex problems

- Critical evaluation capacity

- Work in multidisciplinary groups

With the aim to develop these competences, it has been defined the following learning outcomes (Table 1). On the other hand, all the activities have been designed to be carry out in groups, developing the competence "Work in multidisciplinary groups". 
Table 1. Competences and learning outcomes developed

\begin{tabular}{|c|c|c|}
\hline & Competences & Learning Outcomes \\
\hline 1 & $\begin{array}{l}\text { Ability to search and use } \\
\text { information }\end{array}$ & $\begin{array}{l}\text { Apply the regulation of Royal Decree for a practical case of } \\
\text { animal experimentation }\end{array}$ \\
\hline 2 & $\begin{array}{c}\text { Competence for continuous } \\
\text { learning }\end{array}$ & Be able to perform an experimental design \\
\hline 3 & $\begin{array}{c}\text { Competence for continuous } \\
\text { learning }\end{array}$ & Be able to summarise and present to peers a research article \\
\hline 4 & Critical evaluation capacity & Be able to contrast the information using ITCs. \\
\hline 5 & $\begin{array}{l}\text { Ability to solve complex } \\
\text { problems }\end{array}$ & $\begin{array}{l}\text { Be able to solve complex problems by applying the knowledge } \\
\text { acquired }\end{array}$ \\
\hline
\end{tabular}

\subsection{Teaching activities}

The teaching activities have been designed in order to reach the competences through the learning outcomes. All of them have been organised to be accomplished in groups, with 5 members as maximum.

\subsubsection{Task 1 - Animal experimentation in research}

Thanks a virtual platform (Poliforma T, Sakai system), an on-line server provided to both student and teacher by UPV, the students will have accessible all the guidelines and material necessary in relation to a real research project which includes animal experimentation. Using a form, which will have to be filled, the students should describe the protocol applied in the project and confirm if they followed the animal healthcare rules.

Knowledge to learn: The European regulation on animal experimentation

Skills to develop: Autonomy and personal initiative.

\subsubsection{Task 2 - Carry out your own experimental design}

Once the rules to design a proper animal experimentation have been provided in the previous activity. The students will design an experiment, including an animal model, following the guidelines of the activity using as a reference a set of material (scientific articles, blogs, web of sciences..).

Knowledge to learn: Learn the basic principles of designing an experiment including living beings.

Skills to develop: Oral communication, teamwork, creativity. 


\subsubsection{Task 3-Show me what you know}

With the aim to work on the progressive learning, in the current actibity will work on the learning of presenting the results in attractive format to draw attention to the other scientifics or general public.

Knowledge to learn: Learn how to obtain the most relevant information from a scientific article

Skills to develop: Synthesis, creativity and oral communication.

\subsubsection{Task 4 - Learn to discuss}

Taking as basis the guidelines provided at Poliforma $T$ platform, the students should make their own discussion about the results presented in the task 3. Accordingly, the students should search information to contrast the veracity of these results, supporting their comments in scientific bibliography. The students will have the scientific database provided by UPV to perform the activity.

Knowledge to learn: Learn to contrast the information.

Skills to develop: Critical thinking, ability to seek information.

\subsubsection{Task 5 - Find out who is to blame}

One of the most difficult tasks is to apply the theory to solve a real problem. In the current activity, the teacher will develop a learning module at Lesson section of the Poliforma $T$ platform. This learning module will include a screencast, further additional information, in relation to the effects of drugs or medicines. Afterwards, the students will have a final activity with the description of of a disease. The task will consist in finding out which are the causes of the diseases and which organs are involved.

Knowledge to learn: Learn how drugs/medicines affect the nervous system.

Skills to develop: Logical and deductive thinking.

\subsection{Assessment}

The five teaching activities will have a weigth of $15 \%$ respect to full subject score. The individual score will depend on the indicators of achievement for each learning activity which are as follows: 


\subsubsection{Task 1 - Animal experimentation in research}

Description of the indicators of achievements:

- Knows how to apply the regulations on animal experimentation.

- Is able to identify the most relevant regulation of the Royal Decree.

- Has been demonstrated autonomy to develop the activity

The competence evidence will be the filled form delivered by the student at Poliforma $\mathrm{T}$ platform.

\subsubsection{Task 2 - Carry out your own experimental design}

Description of the indicators of achievements:

- Know how to design a feasible experiment.

- Know the procedure of designing an experiment including living beings.

- Show creativity.

- Develop oral skills.

The competence evidence will be the experimental design document delivered by the student at Poliforma T platform.

\subsubsection{Task 3-Show me what you know}

Description of the indicators of achievements:

- Ability to synthesise.

- Improve the reading comprehension of scientific literature.

- Show creativity.

- Develop oral skills.

The competence evidence will be the results presentation in a poster format delivered by the student at Poliforma $T$ platform.

\subsubsection{Task 4 - Learn to discuss}

Description of the indicators of achievements:

- Ability to find information.

- Critical thinking.

- Ability to transfer theoretical knowledge to resolve practical cases.

The competence evidence will be the document including the discussion of the results presented in the task 3 , and delivered by the student at Poliforma $T$ platform. 


\subsubsection{Task 5 - Find out who is to blame}

Description of the indicators of achievements:

- Ability to solve complex problems.

- Ability to transfer theoretical knowledge to resolve practical cases

- Develop logical thinking.

- Improve deductive skills.

The competence evidence will be the document which includes the resolution of the challenged posed, justifying the response.

The assessment of the different compenteces in each activity will be carry out using a new tool called iRubric, available at Poliforma T platform. Thanks to this tool, iRubric, it will be possible to assess the developed competences in each task using a specific rubric, predesigned to classified the learning outcomes in each activity.

\section{Conclusion}

The objective of this innovative teaching project is to help students to acquire the competences corresponding to the subject "Fisiología Animal y humana" through ICTs. With the aim to reach these goals, an educational methodology known as flipped classroom has been proposed to be applied in two environments: students belong to ARA teaching programme, using English as second-language, and the students belong to Standard group, using Spanish as first language.

In order to evaluate the effectiveness of the teaching project, we will compare the competence assessment reported in previous academic courses, when the teaching programme was not implemented, and after the teaching programme implantation. Finally, motivation will be evaluated through an anonymous questionnaire, in which the students will be asked about the level of satisfaction of the teaching programme, which activities they considered more attractive and which aspects they would change in the future.

The results obtained will be presented to be disseminated in several educational conferences, such as:

- INRED 2018, IV Congreso Nacional de Innovación Educativa y Docencia en Red.

- 4th International Conference on Higher Education Advances (HEAd'18). 


\section{Acknowledgements}

This project has received funding from the Vicerectorado de Estudios, Calidad y Acreditación of the Universitat Politècnica de València (UPV) under Proyectos de Innovación y Mejora Educativa programme (PIME/2017/B/010) and the School of Agricultural Engineering and Environment (ETSIAMN) of the Universitat Politècnica de València (UPV).

\section{References}

Drent, M., \& Meelissen, M. (2008). Which factors obstruct or stimulate teacher educators to use ICT innovatively? Computers \& Education, 51(1), 187-199. https://doi.org/https://doi.org/10.1016/j.compedu.2007.05.001

Halász, G., \& Michel, A. (2011). Key Competences in Europe: interpretation, policy formulation and implementation. European Journal of Education, 46(3), 289-306. https://doi.org/10.1111/j.1465-3435.2011.01491.x

Khan, S. (2012). The one world schoolhouse: Education reimagined. London: Hodder and Stoughton.

Lajoie, S. P., \& Azevedo, R. (2000). Cognitive tools for medical informatics. Computers as Cognitive Tools II: No More Walls: Theory Change, Paradigm Shifts and Their Influence on the Use of Computers for Instructional Purposes, 247-271.

Røkenes, F. M., \& Krumsvik, R. J. (2016). Prepared to teach ESL with ICT? A study of digital competence in Norwegian teacher education. Computers \& Education, 97, 1-20. https://doi.org/https://doi.org/10.1016/j.compedu.2016.02.014

Valtonen, T., Hacklin, S., Kontkanen, S., Hartikainen-Ahia, A., Kärkkäinen, S., \& Kukkonen, J. (2013). Pre-service teachers' experiences of using social software applications for collaborative inquiry. Computers \& Education, 69, 85-95. https://doi.org/https://doi.org/10.1016/j.compedu.2013.07.001 